Foi com imensa satisfação, responsabilidade e emoção que recebi a incumbência de apresentar o Dr. Luiz Gonzaga Gandini Jr., um dos ícones da Ortodontia brasileira que tem lutado incansavelmente para dignificar esta profissão, que necessita de requisitos básicos: ética, caráter, honra, compromisso com o próximo, amizade e vocação, características estas um pouco esquecidas.

É neste contexto que surge o otimismo e a esperança, quando temos a oportunidade de conviver e conhecer de perto o profissional e a pessoa do Prof. Luiz Gandini. Profissionalmente, realizou sua graduação e pós-graduação (especialização, mestrado e doutorado) na Faculdade de Odontologia de Araraquara-Unesp, tornando-se referência e destaque como aluno e professor, pela sua capacidade intelectual, competência científica e acima de tudo um senso clínico admirável. Em 1998, teve a oportunidade de concretizar um sonho, realizando seu pós-doutorado na Baylor College of Dentistry - Dallas e, como esperado, foi eleito professor do ano da Baylor, consolidando seu nome no cenário internacional. Logo em seguida foi convidado para atuar como professor assistente da Baylor e da Saint Louis University, sempre se destacando pela sua facilidade de ensinar os mais diversos temas da Ortodontia, de forma simples, clara e transparente.

Atualmente, além das atividades em sua clínica privada, é chefe do Departamento de Clínica Infantil e professor dos cursos de pós-graduação da Unesp, sempre sendo convidado a ministrar conferências no Brasil e no exterior, ressaltando o congresso da American Association of Orthodontics (AAO) em Las Vegas 2006, onde a Ortodontia nacional foi colocada em alto nível com sua brilhante apresentação. Os mais diversos e atuais temas têm sido ministrados: Ortodontia lingual, arco segmentado, expansões mandibulares, ancoragem esquelética, etc., tornando-o um expoente no universo ortodôntico.

Mas acredito que, de todas estas titulações e realizações profissionais, o mais valioso é o fato do Luiz Gandini ser uma pessoa simples, humilde, amigo dos alunos e com uma característica diferenciada: a extrema valorização da família. Parabéns pela brilhante trajetória de vida, sempre dando a todos os seus alunos e amigos um exemplo de dignidade no exercício da profissão. Por isto, agradeço todos os dias a oportunidade de tê-lo como orientador no sentido mais amplo de uma formação profissional e pessoal.

Aproveitem a entrevista desta figura humana especial e deste profissional exemplar que é o professor e amigo Dr. Luiz Gandini.

\title{
Luiz Gonzaga Gandini Jr.
}

- Curso de Odontologia 1976-79 - FOAr - UNESP.

- Curso de Especialização em Ortodontia - 1983-

84 - FOAr - UNESP.

- Mestrado em Ortodontia - 1989-91 - FOAr

- UNESP.

- Doutorado em Ortodontia - 1995-96 - FOAr

- UNESP.

- Pós-Doutorado - 1998-99 - Baylor College of

Dentistry - Dallas, TX - USA.

- Funções atuais:

- Professor Livre-Docente/Adjunto do Departamento de Clínica Infantil - FOAr-UNESP.

- Assistant Adjunct Clinical Professor - Department of Orthodontic at Baylor College of Dentistry and Saint Louis University.

- Clínico em Ortodontia.

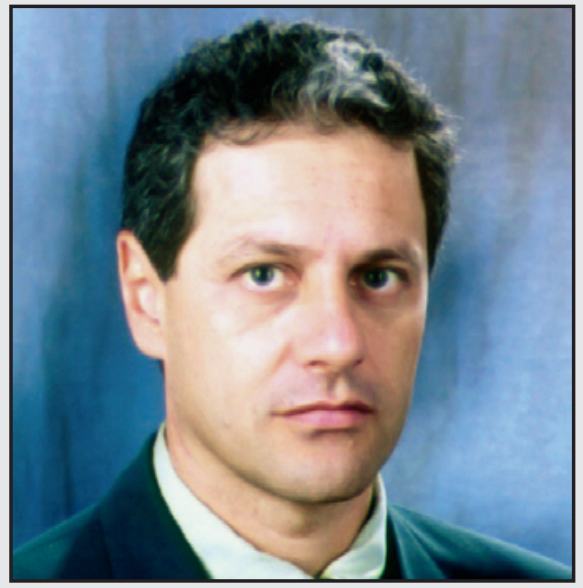

1) Os resultados de seu trabalho pioneiro sobre a distração osteogênica médio sinfiseal são animadores e adicionam ao arsenal cirúrgico-ortodôntico recursos para o tratamento de apinhamentos dentários em arcos atrésicos. Qual sua recomendação e opinião a respeito da aplicação deste procedimento como parte da rotina clínica diária? Ary dos Santos-Pinto
Eu tenho utilizado a distração osteogênica médio sagital da mandíbula (DOMM), clinicamente, há aproximadamente 6 anos, quando pude acompanhar o primeiro trabalho clínico retrospectivo a esse respeito, desenvolvido por Del Santo Jr. ${ }^{1}$, em Dallas (1999). Ao longo do tempo, porém, nós ampliamos um pouco o conceito e estamos interessados agora em utilizar o procedimento como 
uma alternativa às extrações dentárias. Como do primeiro trabalho prospectivo clínico, o qual o professor se refere, eu diria que estamos muito empolgados com os resultados, muito embora acreditemos que seja necessário avaliar os pacientes um pouco mais em longo prazo e outros trabalhos serão necessários para consolidação do procedimento. Os resultados que obtivemos para um aparelho dento-muco-suportado foram satisfatórios e estáveis em curto prazo, sendo que a resposta esquelética correspondeu a 50\% daquela obtida em nível dentário. Iseri e Malkoç² em 2005 também mostraram resultados interessantes utilizando um aparelho dento-ósseo-suportado, inclusive com um grande efeito sobre o osso basal. Eu recomendaria o protocolo de expansão rápida da maxila/DOMM em pacientes preferencialmente Classe I, com apinhamentos de até $8 \mathrm{~mm}$, onde a extração dentária poderia comprometer a estética facial. Poderíamos dizer que seria uma maneira de seguir a tendência ortodôntica expansionista atual, mas procurando trabalhar também as bases ósseas, ao invés de somente o processo dentoalveolar.

2) Qual é o estágio de evolução da técnica do arco lingual no Brasil? Qual o impacto desta técnica na rotina de atendimento clínico e - grau de dificuldade adicional esperado no tratamento das más oclusões, principalmente nos casos de extração onde é necessária a utilização de recursos mecânicos para o fechamento de espaços? Ary dos Santos-Pinto

A técnica do arco lingual no Brasil tem seguido a tendência mundial de crescimento ao longo dos últimos anos. Esse crescimento tem sido lento, mais sustentado e mais embasado do que aquele ocorrido no início da década de 80 . Eu diria que hoje no Brasil essa técnica é viável e isso se deve a um grupo pequeno de colegas que tem se esforçado para fazê-la de maneira séria e combatendo aqueles que tinham o único interesse de se beneficiar financeiramente com a tentativa de ensino da mesma. O impacto clínico dessa técnica ainda é pequeno, pois um número reduzido de pacientes a procura e tem condições de custeá-la. Ela é um bom referencial para o marketing e pode trazer para o consultório pacientes que procuram a mesma e que acabarão indo para o aparelho estético. A tendência atual dessa filosofia, nos Estados Unidos, tem sido de evoluir para aparelhos e arcos individualizados (lingual care) e a própria Ormco colocou no mercado uma nova geração de braquetes (STB) com o objetivo de facilitar a montagem, bem como ser mais confortável e dar resultados mais rápidos. No que diz respeito aos tratamentos e suas dificuldades, em comparação com o aparelho convencional, ela tem a tendência de aumentar um pouco o tempo de tratamento e oferecer maior dificuldade na fase de finalização, porém recursos técnicos foram desenvolvidos para se controlar com segurança as várias alternativas de tratamento, inclusive com extrações dentárias. $\mathrm{O}$ ideal seria que o profissional interessado em iniciar nessa técnica fizesse um curso ou tivesse um treinamento com um colega que tenha experiência com a mesma, para tornar o caminho de seu domínio mais curto e com menores tropeços. Nós temos ensinado a técnica lingual nos cursos de especialização e mestrado/doutorado em Araraquara, com o objetivo de que mais profissionais possam executá-la e se abra o leque de possibilidades para os pacientes, bem como mais pessoas ajudem a desenvolvê-la ainda mais.

3) Baseado na experiência vivenciada e no contato que você tem mantido com os alunos dos cursos de pós-graduação da Baylor College of Dentistry de Dallas - Texas e da Universidade de Saint Louis, qual a diferença na formação básica do ortodontista nos Estados Unidos e no Brasil? Ary dos Santos-Pinto

Várias diferenças podem ser enumeradas, mas também temos algumas semelhanças e, em termos técnicos, eu poderia dizer que somos muito parecidos, pois sofremos muita influência de lá, mas em primeiro lugar gostaria de falar um pouco da diferença existente em relação ao clínico geral, que na minha percepção tem interferência na nossa especialidade. Dois fatores principais fazem a diferença: um deles está relacionado ao número 
de escolas de Odontologia, onde eles têm aproximadamente 50 cursos para uma população de 300 milhões de habitantes e nós 180 cursos para 180 milhões de pessoas. O segundo fator está relacionado ao controle de qualidade, onde o CD americano necessita fazer uma prova de proficiência, após o término do curso, para ser autorizado a exercer a profissão. Ao mesmo tempo existe um controle governamental e classista sobre a quantidade de novos CD entrando no mercado e sobre os que se aposentam. Em relação à Ortodontia, a formação nos Estados Unidos é feita praticamente toda em cursos de mestrado e em tempo integral, propiciando assim uma formação básica mais consistente do que a grande maioria dos programas existentes no Brasil. A grande maioria dos programas, nos Estados Unidos, não tem mais que 6 alunos por ano. Além disso eles têm mais recursos financeiros para pesquisas e, dessa forma, criam novas tecnologias e têm um nível superior ao nosso neste aspecto. A grande maioria dos programas americanos tem bem definido quais são os professores pesquisadores e em tempo integral, e ao mesmo tempo tem um número grande de professores clínicos em tempo parcial, muitos deles até voluntários e sem remuneração. Por exemplo, no programa de Ortodontia do Baylor College of Dentistry existem quatro professores em tempo integral e aproximadamente dezoito em tempo parcial. As maiores diferença que eu percebo hoje, relacionada aos dois países, são de ética e responsabilidade, uma vez que temos uma abertura indiscriminada de cursos de Ortodontia, sem o menor controle de qualidade. Aqueles cursos que funcionam no Brasil em tempo integral, vinculados a boas universidades, têm condições de formar o aluno tão bem quanto aos formados nos Estados Unidos, porém isso tem se tornado cada vez mais a exceção. A regra geral são cursos com freqüência cada vez mais espaçada e com uma carga horária que muitas vezes não é completamente cumprida. Isso resulta em profissionais acreditando que sabem muito mais do que na realidade o sabem e em um mercado canibal, onde a ética profissional é deixada em segundo plano.

\section{4) Quais são os requisitos para se tornar um ortodontista bem sucedido e qual o ca- minho a trilhar na obtenção da excelência em Ortodontia? Ary dos Santos-Pinto}

De forma geral podemos observar que em toda profissão liberal, como a Odontologia, existem duas formas gerais de se tornar bem sucedido: 1) por meio da competência baseada em conhecimento científico e boa formação e 2) por meio político, onde o profissional, mesmo sem muita competência, consegue uma projeção perante a sua sociedade e se torna financeiramente bem sucedido. Vamos nos ater à primeira opção, uma vez que não considero a segunda adequada. Assim sendo, o ideal para quem pretende iniciar na carreira ortodôntica seria ter como meta principal estudar em um programa de pós-graduação de muito boa qualidade. Na minha opinião, os melhores programas de pós-graduação ainda são os mestrados acadêmicos (em tempo integral) e, dessa forma, essa deveria ser a meta final. Existe uma tendência atual de os alunos saírem da graduação e irem direto para as especializações, muitas delas com um nível de professores também não bem formados e, dessa forma, incapazes de formarem bem o novo ortodontista. É necessário entender que ser professor é muito mais que ensinar o aluno a fazer o que você faz no seu dia-a-dia. É necessário criar um espírito crítico e um grau de conhecimento que permita a tomada de decisões baseada em evidências lógicas e científicas. A grande maioria dos programas de pósgraduação em nível de especialização e mestrado profissionalizante forma o novo ortodontista na base da "receita de bolo" e do "faça o que eu faço que funciona". E o pior dessa história é que o aluno recém formado acredita que sabe tudo e que está fazendo a melhor Ortodontia do mundo, porque assim the foi ensinado. Novamente ética e responsabilidade deveriam imperar. Quando as pessoas não as exercem, os órgãos controladores deveriam fazê-lo. Por fim, a excelência em Ortodontia poderia ser atingida após alguns anos de exercício profissional adequado, para aqueles que obtiveram uma boa formação. No Brasil, eu 
acho que o certificado de excelência é atestado pelo Board Brasileiro de Ortodontia ou quando o profissional consegue ter o respeito e o reconhecimento da maioria dos colegas ortodontistas de destaque do país. Como sugestão para atingir a excelência em Ortodontia poderia enumerar: 1) sempre acredite que você ainda precisa aprender mais e mantenha a atualização profissional em evidência; 2) tente acabar seus casos de forma perfeita e impecável, mas jamais acredite que ainda não poderia fazer melhor; 3 ) seja ético com seus pacientes e colegas; 4) nunca perca o romantismo ortodôntico que te guiou para a especialidade; 5) tenha consciência de suas limitações e jamais coloque o resultado financeiro como a primeira meta a ser atingida.

5) Com base no seu profundo conhecimento sobre a técnica do arco segmentado, qual a sua opinião a respeito da aplicação dos recursos mecânicos preconizados por técnicas tais como alça T, alça retangular e cantilever? Ary dos Santos-Pinto

Tenho acompanhado a técnica do arco segmentado de Burstone desde sua introdução no Brasil, pelos idos de 1985, e nesses anos de experiência clínica e de ensino em Araraquara pude encontrar a real posição para a mesma dentro de um consultório ortodôntico. É sabido, por meio da literatura, que existem dois meios gerais de se abordar pacientes em Ortodontia fixa: 1) por meio do sistema de arcos ideais (forma de arco) ou 2) pelo sistema de forças. A técnica do arco segmentado trabalha baseada no princípio do sistema de forças e é bem indicada para movimentos que demandam grandes extensões e para movimentar-se dentes com grande ancoragem, como caninos e molares. Nessa linha de raciocínio, trabalha-se de forma bem definida, com uma unidade reativa ou de ancoragem e com uma unidade ativa ou a ser movimentada. Os recursos de desenho de molas citados na questão são específicos para determinados tipos de movimentação e, como toda a abordagem pelo sistema de força, muito úteis quando bem indicados. O segredo é mesclar as duas formas de tratamento e utilizar, em cada situação, a que melhor se adeque ao fim desejado. Como uma colocação clínica, poderia dizer que tenho utilizado aproximadamente 15\% de mecânica segmentada em certas fases do tratamento e que os outros $85 \%$ tenho tratado baseado na forma do arco, com algum tipo de filosofia Straight wire. Considerando-se que a unidade ativa é bem definida no início de tratamento e que o sistema de forças pode ser bem desenhado, essa filosofia se destaca por um melhor controle das unidades de ancoragem, com menores efeitos colaterais e geralmente uma resposta biológica muito bem controlada, por trabalhar com grandes distâncias inter-braquetes, baixas proporções carga/deflexão e proporção momento/força adequada e conhecidos durantes a desativação das molas.

6) Qual elemento de diagnóstico você considera primordial no planejamento de tratamento de adultos, aquele que define a sua conduta em casos limítrofes? Roberto Carlos Bodart Brandão

O diagnóstico de um caso é feito por um conjunto de informações, que normalmente são pesadas em conjunto para definir a tomada de decisão, e é exatamente esse conjunto que contribui para o poder na identificação do problema. Porém, no caso de separar-se em elementos individualizados, e especificamente para pacientes adultos e casos limítrofes, eu diria que dois fatores são determinantes: 1) a queixa principal do paciente e 2) a condição periodontal do mesmo, no caso de pensar-se em expansão para futura contenção permanente ou camuflagens ortodônticas. No adulto, a queixa principal é melhor definida e a maioria das vezes o paciente sabe bem o que espera do tratamento ortodôntico. Por outro lado, a saúde periodontal é o fator que limita tratamentos mais ou menos audaciosos.

7) Em adultos portadores de mordida cruzada posterior, quais os recursos e limitações para o tratamento, considerando que a opção 
cirúrgica foi descartada pelo paciente? Roberto Carlos Bodart Brandão

Se a mordida cruzada posterior for do tipo dentária, eu consideraria a expansão com inclinações dos elementos envolvidos e posterior contenção por longo prazo. No caso de mordidas cruzadas mais complexas e aquelas consideradas esqueléticas, a opção de uma expansão cirurgicamente assistida seria mandatória, em minha experiência, porém se a mesma, por alguma razão, fosse descartada, provavelmente eu ponderaria manter o cruzamento posterior inicial e tentar um ajuste oclusal por desgastes no final do tratamento. Caso a condição periodontal do paciente seja muito boa, haveria a possibilidade de inclinações compensatórias e a utilização de contenções definitivas fixas ou removíveis pelo resto da vida, à noite e de forma alternada.

8) No seu consultório, qual a porcentagem de casos em tratamento com aparelhos linguais? Esta técnica deverá substituir ou conviver com a Ortodontia convencional, no futuro da sua clínica? Roberto Carlos Bodart Brandão

A porcentagem de tratamentos com aparelhos linguais em minha clínica ainda é muito pequena, provavelmente $2 \%$, se eu estimar um valor, e acredito que seja por dois fatores principais. Um deles é pela característica da cidade que trabalho, de médio porte e com um poder aquisitivo limitado. Em segundo lugar, pelo valor cobrado para esse tipo de tratamento, que limita ainda mais o acesso de pacientes. Poderíamos falar ainda em um outro dado que seria talvez interessante: qual o porcentual de pessoas que procuram por tratamento lingual? E aí o percentual poderia ir perto da casa dos $8 \%$, o que ainda é um número muito pequeno no universo ortodôntico total, sendo que provavelmente, uma boa parte da população ainda não conheça essa forma de tratamento. Nesse raciocínio é fácil entender que a técnica lingual irá ainda conviver com a convencional por muito tempo e talvez algum dia possa substituí-la, mas será necessária muita evolução e redução de custos para que isso venha a ocorrer.

\section{9) Considerando os dogmas da Ortodon- tia: manutenção da forma de arco e não pro- clinação de incisivos, qual o seu grau de to- lerância no tratamento de adultos? Roberto Carlos Bodart Brandão}

Ainda acredito que não dispomos, na literatura, de suporte suficiente para não aceitarmos esses dois dogmas como adequados para a maioria dos pacientes e, assim sendo, procuro em todos os planos de tratamentos respeitar esses limites, principalmente nos adultos. É natural que, em alguns casos, para se manter como prioridade a estética facial, sejamos forçados a não extrair e, para isso, somos obrigados a expansões e/ou proclinações. Quando a decisão for nessa direção, as mesmas deveriam ser feitas em um grau não exagerado, sempre considerando-se um plano de contenção mais longo que o normal. Estabelecer um valor numérico é bastante difícil e eu diria que a decisão de fazê-lo, e em que grau, ainda é subjetiva. Fatores como a experiência profissional, bem como a formação do mesmo, influenciarão em aceitar um limite maior ou menor.

10) Miniplacas ou miniimplantes, como ancoragem esquelética? Roberto Carlos Bodart Brandão

Não há dúvida que a ancoragem esquelética é um excelente recurso para muitos casos e veio definitivamente para quebrar alguns paradigmas na Ortodontia, porém, como muitas outras coisas que surgiram, a ancoragem esquelética ainda está encontrando sua adequada posição e alguns excessos têm sido cometidos, tentando-se tratar casos que provavelmente seriam cirúrgicos com a utilização da mesma. Os miniimplantes ou microparafusos ou ainda DAT - dispositivos temporários de ancoragem - têm crescido na aplicação clínica por serem menos invasivos que as miniplacas e acredito que, no futuro, tudo que se fará em termos de ancoragem absoluta será por meio de miniparafusos. Porém, ainda hoje, as miniplacas têm sido muito bem indicadas para casos onde são necessárias maiores quantidades de força ou apoio à distância, como por exemplo, para intrusão em 
bloco ou distalizações de segmentos. Embora mais agressivas por necessitarem de cirurgia para instalação e remoção, são colocados mais parafusos num mesmo dispositivo e, portanto, tem mais sustentação. Além disso, são suportadas, geralmente, em uma área óssea distante daquela que será movimentada. Têm, entretanto, a desvantagem de transfixarem a mucosa e, como conseqüência, apresentam maior possibilidade de infecções no pós-operatório.

11) De tudo que tem lido e pesquisado ultimamente, qual a informação que mudou de forma significativa a sua conduta clínica? Roberto Carlos Bodart Brandão

Desde o meu início na Ortodontia, diria que a evolução técnica que mais me influenciou na clínica foi o advento dos braquetes straight wire. Essa descoberta tecnológica permitiu finalizar os casos com um nível de excelência e conforto maior e com um esforço muito menor. Porém, do ponto de vista científico, algumas coisas têm mudado minha conduta clínica: a primeira delas foi o grande avanço da cirurgia ortognática e cirurgias menores, como expansão rápida assistida cirurgicamente e distração osteogênica, que fizeram com que eu mudasse a forma de definir o melhor plano de tratamento para o meu paciente, possibilitando muito mais enfoque na estética facial. A segunda foi a maior aceitabilidade de arcos um pouco mais amplos e expandidos, mas ainda com alguma ressalva. E a terceira e mais recente o desenvolvimento do DAT, que tem se mostrado propenso a derrubar alguns paradigmas na nossa especialidade. Ainda do ponto de vista filosófico e conceitual, a possibilidade de se tratar casos com mecânicas segmentadas teve uma grande influência na minha conduta clínica atual.

12) Cite uma decepção na Ortodontia/Ortopedia facial que poderia servir de lição para os jovens que iniciam esta jornada? Roberto Carlos Bodart Brandão

Eu não tive grandes decepções com a Ortodontia/Ortopedia como ciência, mas estou tendo uma grande decepção na maneira como o ensino dessa especialidade tem caminhado ao longo dos anos. Quando iniciei na especialidade existiam apenas três cursos de pós-graduação na área, em nível de mestrado. É certo que era muito pouco para formar mestres/especialistas para um país do tamanho do Brasil, mas hoje o que vemos é uma quantidade imensurável de cursos de especialização. Dessa forma, caminhamos de um extremo para outro, sem o menor controle de qualidade e com uma tendência cada vez maior de se nivelar por baixo. Como disse anteriormente, os cursos de mestrado em tempo integral são os que formam melhor os profissionais, mas poucos professores têm tido interesse em mantê-los, pois nas entidades públicas eles são gratuitos e os docentes não ganham mais por essa atividade. Assim sendo, estou vendo uma grande tendência deles desaparecerem e serem substituídos por mestrados profissionalizantes (em tempo parcial) e pelas especializações (também parciais). Como resultado temos tido grande decepção profissional com um número de pacientes cada vez menor, com um custo de tratamento para o paciente absurdamente baixo, com um aumento das despesas fixas para o profissional e com uma qualidade final de tratamento muito ruim. Como conselho diria aos jovens: trabalhem no sentido de reversão desse quadro caótico, valorizando sua formação em centros de bom nível e pressionando os órgãos responsáveis para que realmente exerçam sua função e controlem a qualidade das escolas formadoras.

\section{3) Do seu convívio com o professor e ami-} go Joel Cláudio da Rosa Martins, que lições você poderia dividir conosco? Roberto Carlos Bodart Brandão

Extremamente prazeroso relembrar o amigo Joel e as inúmeras lições que foram por ele deixadas. A primeira lição que aprendi com o mestre Joel foi que ser professor é ensinar ao aluno muito mais do que o que ele vai fazer como ortodontista e sim desenvolver no mesmo um espírito crítico e um conhecimento amplo sobre toda a especialidade. Além disso, zelava pela ética e defendia e 
praticava o compromisso do "seja sempre honesto com seus alunos e consigo mesmo". Para ele, em ciência a verdade deve estar sobre todas as coisas e toda pesquisa e ensinamento deve sempre relatar a verdade dos resultados. No aspecto pessoal ele era um indivíduo com muita alma e amor interior e, dessa forma, muito preocupado em respeitar o espaço do outro. Com um jeito muito franco e direto, algumas vezes não bem entendido, era crítico e ao mesmo tempo questionador, respeitando porém os pontos de vista dos outros. $\mathrm{Na}$ nossa escola representou o lado do pensador e organizador, sempre ponderando muito sobre qual o melhor caminho a ser seguido e qual a forma mais adequada de se manter a excelência. Nos deixou um grande legado do ponto de vista científico, mas sem dúvida o maior deles foi pessoal e humano.

14) Quais são as vantagens e desvantagens da distração osteogênica médio sagital da mandíbula (DOMM) em comparação com a terapia de extrações para pacientes em crescimento com apinhamento inferior? Peter $\mathrm{H}$. Buschang

A DOMM inicialmente foi desenhada para expansão de mandíbulas atrésicas, em qualquer faixa etária, mas com o passar do tempo um novo enfoque tem sido dado a essa abordagem de tratamento e o novo objetivo tem sido o de minimizar o número de casos de extrações dentárias, por meio de uma expansão superior e inferior. Assim sendo, para se ter sucesso pleno na disjunção maxilar é necessário que o paciente tenha crescimento. Como vantagens desse procedimento poderíamos citar a manutenção dos pré-molares na boca do paciente, com um tratamento possivelmente mais rápido, uma vez que não teria a fase de fechamento de espaços das extrações. Outra vantagem que poderia ser abordada seria um perfil final menos retruso, uma vez que as extrações têm a tendência de achatar o perfil final do paciente. Em relação às desvantagens, a principal delas é a necessidade de uma intervenção cirúrgica menos convencional e menos aceita pelos pacientes do que a cirurgia para extrações. Outro fator a ser considerado se- ria, como um procedimento mais recente, a menor informação de que dispomos do comportamento em longo prazo da DOMM em relação às extrações dentárias.

15) Como você vê a mudança do ensino da Ortodontia no Brasil para os próximos dez anos? Peter $\mathrm{H}$. Buschang

Vejo o ensino da Ortodontia no Brasil acompanhando, como sempre, a tendência dos Estados Unidos da América, porém com uma característica de mercado de trabalho completamente diferente, uma vez que estamos colocando de forma indiscriminada profissionais no mesmo. Dessa maneira acredito que nos próximos dez anos teremos duas características de programas formadores: o primeiro deles com um nível muito alto, melhorando o número de pesquisas e publicações internacionais, esses estão próximos da tendência dos países onde a Ortodontia é de ponta; e o segundo grupo, formado por programas fracos e que se preocupam em treinar um tecnicista da área, contribuindo dessa forma para uma piora na qualidade dos tratamentos oferecidos à população. O grande problema é que o segundo grupo predominará e, assim sendo, o nível do tratamento ortodôntico oferecido para a comunidade irá cair, em comparação aos países que mantiverem a formação dos profissionais sob um melhor controle.

16) Qual é o potencial para expansão da mandíbula quando comparada com a maxila? É possível aumentar-se a largura das estruturas basais? Quanto estável você espera ser a expansão da maxila e da mandíbula? Peter $\mathrm{H}$. Buschang

O potencial de expansão da mandíbula, quando comparado com o da maxila, é menor, mas não sei precisar o quanto, porém com certeza é possível aumentar-se a largura das estruturas basais de ambos. Para essa afirmação estou pensando em disjunção rápida da maxila e distração osteogênica médio sagital na mandíbula, em idade compatível. O primeiro procedimento está mais do que aceito e consagrado, possibilitando ganho basal na maxila. 
No segundo, estudos recentes têm mostrado a possibilidade de expansão basal da mandíbula, quer seja com aparelhos ósseo ou dento-suportados. Quanto à estabilidade, novamente a disjunção palatina não deixa dúvidas de sua eficiência em longo prazo. Quanto à DOMM, os poucos trabalhos existentes mostram uma boa estabilidade, mas não tão em longo prazo. Clinicamente falando e com minha experiência nessa área, tenho uma boa expectativa de estabilidade em longo prazo. Assim sendo, como disse anteriormente, acredito que com a dupla disjunção maxilar/DOMM seja uma boa opção a não extração de pré-molares, com um ganho real de base óssea superior e inferior.

1. DEL SANTO JR., M. Long-term skeletal and dental effects of mandibular midsymphyseal distraction osteogenesis. 1999. (Mestrado em Ciências Odontológicas) - Departamento de Ortodontia, - Baylor College of Dentistry, Dallas, 1999.

2. ISERI, H.; MALKOÇ, S. Long-term skeletal effects of mandibular symphyseal distraction osteogenesis. An implant study. Eur J Orthod, Oxford, v. 27, no. 5, p. 512-517, 2005.

\section{Ary dos Santos-Pinto}

- Possui graduação em Odontologia pela Universidade Estadual Paulista Júlio de Mesquita Filho (1980), mestrado em Odontologia pela Universidade Federal do Rio de Janeiro (1983), doutorado em Odontologia pela Universidade Federal do Rio de Janeiro (1985) e pós-doutorado pela Baylor College of Dentistry (1997). Atualmente é Professor Livre-Docente e Adjunto do Departamento de Clínica Infantil - Ortodontia - da Faculdade de Odontologia de Araraquara - Universidade Estadual Paulista Júlio de Mesquita Filho (UNESP), revisor da Revista Dental Press de Ortodontia e Ortopedia Facial e revisor da Revista Clínica de Ortodontia Dental Press.

\section{Roberto Carlos Bodart Brandão}

- Possui graduação em Odontologia pela Universidade Federal do Espírito Santo (1987), mestrado em Odontologia pela Universidade Federal do Rio de Janeiro (1991) e doutorado em Odontologia - área de Ortodontia - pela Faculdade de Odontologia de Araraquara - Universidade Estadual Paulista Júlio de Mesquita Filho (2003). Atualmente é Professor Adjunto da Universidade Federal do Espírito Santo. É revisor da Revista Dental Press de Ortodontia e Ortopedia Facial. Foi presidente da Sociedade dos Ortodontistas do Espírito Santo - SOES.

\section{Peter Buschang}

- Atualmente é Professor titular e diretor de pesquisas em Ortodontia da Baylor College of Dentistry - Dallas - TX. Realizou o doutorado na Universidade do Texas - Austin - USA, estudando crescimento e desenvolvimento humano, realizou o pós-doutorado no departamento de Ortodontia da Universidade de Connecticut-USA e foi pesquisador na seção de Ortodontia do centro de pesquisas de crescimento da Universidade de Montreal - Canadá. É revisor da American Journal of Orthodontics and Dentofacial Orthopedics. Os focos das suas pesquisas estão no crescimento craniofacial, adaptação do desenvolvimento ao tratamento ortodôntico e cirúrgico e na função oro motora. 